\title{
Pobres y criminales. Beneficencia y reforma penitenciaria \\ en el siglo XIX en México
}

Antonio Padilla

El Colegio de México

INTRODUCCIÓN

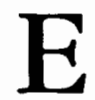

1 presente texto tiene entre sus propósitos presentar algunas notas sobre el estudio de la pobreza y la criminalidad, así como las relaciones que se establecieron, dentro del pensamiento social decimonónico. Asimismo pretende destacar los esfuerzos de la elite política por impulsar una reforma de las instituciones dedicadas a la promoción y patrocinio de la caridad privada, herencia en gran medida de la etapa colonial dentro del proceso de formación de una nueva organización social, así como de la fundación de establecimientos carcelarios que respondieran a las necesidades de control social que demandaba la presencia de nuevos grupos sociales que se expresaba, entre otras formas, mediante la aparición de nuevos delitos, y de las ideas que en torno a las cárceles se formularon, su función y los objetivos que debían cumplir.

Durante el siglo XIX, la elite política mexicana mantuvo un interés ambiguo ante el tema de la pobreza y los pobres, que iba de una preocupación constante hasta la indiferencia rampante.

El pensamiento católico influyó en la valoración de esa condición social al atribuirle, entre otras cosas, cualida- 
des y virtudes relacionadas con el quehacer cotidiano de la Iglesia $y$ del resto de la sociedad. En general, este pensamiento juzgó inherente a la naturaleza humana la desigualdad social, pero ubicó a la pobreza y a los pobres en otro orden, más allá de la propia jerarquización social de la Iglesia: ser pobre era un estado de gracia. ${ }^{1}$

Por tanto, una parte de la riqueza debía destinarse a dispensarles algunos goces $y$, por añadidura, los ricos estaban comprometidos moralmente a ofrecérselos međiante la caridad, administrada por la Iglesia. La porción que correspondía a los pobres era lo superfluo cie los ricos, una vez que éstos hubieran satisfecho sus necesidades. ${ }^{2}$

1 Las nuevas realidades que impusieron las relaciones mercantiles y la desorganización de la sociedad colonial obligó a la Iglesia católica a modificar su percepción de la pobreza hasta sostener una idea ambigua con respecto de los pobres: por una parte, mantenía la fidelidad a la formulación bíblica de Cristo como símbolo del pobre y de la pobreza, y por la otra tendía a diferenciar grados, motivaciones y condiciones de la pobreza. En función de ello definió quiénes y cómo recibirían la caridad.

2 El concepto católico de caridad "transforma la humildad espiritual en un impulso hacia Dios y tiende a aliviar la humillación material y social de los pobres". En contraste, la avaricia fue considerada como el motor de la sociedad moderna. El escritor mexicano José Campa y Argüelles critic 6 acremente la idea de la caridad porque exageraba "el valor que se le concedía a la pobreza, pues al unir la holgazanería a las ideas de la bienaventuranza celestial, hacía que los hombres despreciaran el trabajo y consideraran injusta la pobreza, lo que iba en perjuicio de la riqueza". Afirmaba que la avaricia tenía un límite: el propio interés individual. Mollet, Pobres, 1988, p. 155; González Navarro, Pobreza, 1985, pp. 41-42.
En el transcurso del siglo XIX, el proceso de secularización de la vida cotidiana propició la aceptación de nuevas ideas en el pensamiento social, especialmente las que venían del liberalismo mexicano con su proclama de igualdad y libertad. Al mismo tiempo, modificó el marco de interpretación social y dio por resultado visiones distintas a la mantenida por la Iglesia católica, de acuerdo con los cambios experimentados en la esfera de la economía y la sociedad. ${ }^{3}$

Una nueva moralidad se gestó junto con una nueva idea de la pobreza. Ésta fue también secularizada y perdió su carácter de gracia. En el centro de esta idea estaba el individuo, quien tenía obligaciones y deberes que, según los observara, podían redituarle estabilidad y mejoramiento económico y social. La clave de su ascenso estaba en el trabajo honrado, la sobriedad, el ahorro, en una palabra, en la vida austera. ${ }^{4}$

3 El pobre, en la terminología catolica, es aquel que tiene ingresos precarios o que pueden faltarle en alguna circunstancia. Esa precariedad o carencia es transitoria. En Europa, a fines del siglo xrv, el significado religioso de pobre adquirió diferentes acepciones. La distinción más importante se estableció con el pobre labo. rioso que enfrentaba dificultades económicas y no podía cubrir sus necesidades por medio del trabajo. En contraste, se empleo la palabra mendigo para designar a aquellos individuos que se presumían eran perezosos o se inclinaban por la delincuencia. Al primero se le dio un sentido positivo, pues deseaba salir de su situacion por medio de su propio esfuerzo, mientras que el segundo tuvo una definición negativa, pues hacía de la mendicidad una actividad lucrativa, pero de desprestigio social. Guglielmi, Marginalidad, 1986, p. 62; Mollet, Pobres, 1988, p. 11.

4 Véanse Guerrero, Génesis, 1901, y López Portillo y Rojas, Escritos, 1910. 


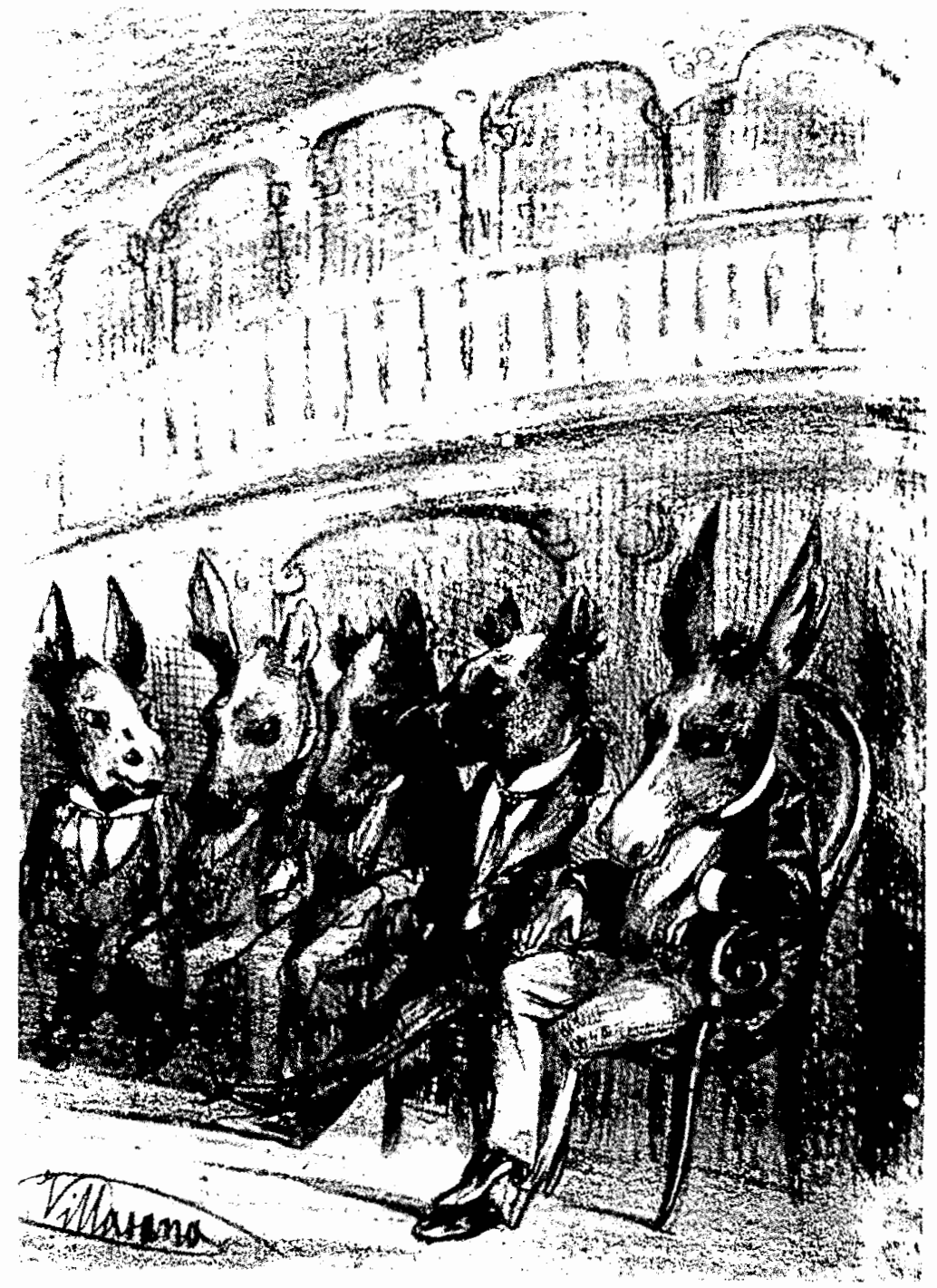

Lo que abundara en el proximo Congreso. 
Los impulsos filantrópicos y humanitarios se reservaron a la esfera de lo privado y la obligatoriedad de la caridad pasó a ser una opción individual a fin de destinar parte de la riqueza a atenuar las penalidades de los pobres. La esfera moral se separó de la economía.

Fue hasta las últimas tres décadas del siglo XIX cuando la pobreza y los pobres fueron objeto de análisis y estudio sistemáticos. Esta situación se explica-entre otros factores-por la estabilidad política durante el porfiriato, lo cual permitió dirigir la atención de los pensadores sociales hacia el estudio de la sociedad mexicana; a la promoción y aplicación de una política económica orientada a la industrialización de algunas ramas productivas, lo que propició migraciones intrarregionales; a la movilidad de la fuerza de trabajo a otras actividades y ocupaciones, así como a propiciar nuevas relaciones y grupos sociales, etcétera.

El conjunto de estas transformaciones arrojó un rico material de reflexión en torno a sus efectos en la esfera de la economía, la política y lo social, aunque lamentablemente no dio un fruto igualmente prolífico en descripciones sociales, sobre todo en relación con las condiciones de vida de los pobres. 5

Entre los esfuerzos más significati-

5 Tal vez una excepción fue el escritor y novelista José Rivera y Río, quien dedicó cinco novelas a escudrif́ar la vida de los pobres. Sin duda, este novelista lego un rico y valioso material para conocer las condiciones de vida de los pobres entre los ańos cincuenta y sesenta del siglo pasado. Con justicia, podría atribuírsele el título del "descubridor de los pobres" en México, al igual que su homólogo inglés Henry Mayhew. vos en el ámbito del pensamiento social mexicano se cuenta el de tratar de establecer las causas de la pobreza y sus efectos en la sociedad mexicana. La pobreza, se pensaba, obedecía a razones más terrenales que divinas: era una condición individual y voluntaria ya fuese porque no existieran intenciones o móviles de mejoramiento social o bien porque se prefiriera dedicarse a actividades u ocupaciones que, sin ser consideradas honorables, si permitían una vida de holgura y comodidad. También se atribuía a la herencia biológica o a los atavismos culturales y sociales, lo que en este caso hacía casi imposible modificar esa condición.

\section{LAS MISERIAS SOCIALES}

Una de las coincidencias más sobresalientes entre la mayoría de los autores fue que la pobreza -la cual había alcanzado dimensiones de verdadero escándalo, al grado de que algunos de ellos sostenían que se vivía en un estado de miseria pública-, tenía entre sus principales causas la devastación que había padecido el país con la guerra civil y la invasión extranjera. Sus secuelas se manifestaban en la ausencia de inversión y en la desorganización de la industria, el comercio y la agricultura, con la consecuente expulsión de la mano de obra que buscaba dónde ocuparse y, cuando ello no era posible, recurría a actividades que revelaban la gravedad de la crisis social que enfrentaba la nación: a la mendicidad generalizada, a la vagancia, a la prostitución, a los juegos de azar y, en el último escalón de las conductas anti- 
sociales, a la delincuencia en todas sus manifestaciones. El periódico La Libertad hacia notar que el problema fundamental del país era la inseguridad pública porque había impedido atraer la inversión de los ricos y éstos preferían emigrar a otros países. El temor a ser asaltados y robados explicaba la indiferencia y apatía para promover el progreso del país y demostraba, a su vez, el grado de desorganización del mismo y la falta de patriotismo de los ricos. Por su parte, el periódico la Ilustración Católica justificaba tal actitud y explicaba que, en todo caso, la anarquía que padecía el país se debía a las doctrinas liberales y al desquiciamiento que habian provocado. ${ }^{6}$

Algunos pensadores de la época atribuyeron la falta de empleos a otros factores. Por ejemplo, analizaban así las consecuencias que traía consigo el proceso de industrialización, y la libre importación de mercancías: "La libre importación de mercancías y de los efectos extranjeros, es la causa de la miseria en que se encuentra nuestro pueblo tiempo hace."7

A esta situación, decían, se agregaba un elemento fundamental que contribuía a la degradación moral y social de grandes sectores de las "clases me.

${ }^{6}$ La Libertad, 24 enero 1879; La llustración Catolica, 31 enero 1879; El Siglo Diez y Nueve, 30 enero, 10 febrero, 14 agosto 1877 ; El Monitor Republicano, 15 febrero 1877 . Era cal el estado de pobreza que estos periódicos advirtieron: "Hoy no caben los enfermos en los hospitales, ni en las casas de beneficencia los pobres, y ios fondos públicos no bastan para aliviar a los innumerables que llaman a las puertas de la caridad pública."

${ }^{7}$ El Monitor Republicano, 16 enero 1877; 1 septiembre 1877 . nesterosas": la carencia de instrucción y enseñanza que moralizara, educara e inculcara el amor por el trabajo; sus manifestaciones eran elocuentes en todo el país, pero acusaba mayor gravedad en la capital de la república. La pobreza campeaba, sobre todo, en las ciudades convertidas en el principal foco de corrupción moral y desorganización social. ${ }^{8}$

En el extremo de la pobreza se ubicaba la mendicidad, la cual fue tasada con un criterio utilitarista al atribuirle un móvil de cálculo, como a cualquier otra profesión lucrativa. Ésta fue considerada la "verdadera plaga de nuestra sociedad". No pocos escritores hicieron notar, unas veces en tono dramático y otras con repulsión, las consecuencias más nocivas de la mendicidad, en especial de la infantil. Para ellos, la ciudad de México se había convertido en una "ciudad de mendigos", cubierta en su superficie por una "capa dorada", bajo la cual se descubrían las "miserias más asquerosas".?

En el fondo de esas descripciones había una preocupación más pro-

8 El Monitor Republicano, 16 enero 1877; El Siglo Diez y Nueve, 21 agosto 1877.

9 La metáfora de una plaga que se extiende por el país fue muy similar a la descrita por un escritor francés en el siglo xviI para referirse a un problema semejante. En este caso se tratabn de una plaga de langostas que se abatía sobre la campiña francesa: "Son insectos voraces que destruyen cotidianamente la subsistencia de los labradores. Son, para hablar sin metáforas, tropas enemigas diseminadas sobre la superficie del territorio, que viven sobre él a discreción como en país conquistado y que imponen contribuciones con el título de limosna". Vease Foucault, Vigilar, 1981, p. 81. 
funda, que más tarde fue adquiriendo carta de naturaleza dentro del pensamiento social. Debía reconocerse que la mendicidad generalizada obedecía a factores anormales, dado que el país atravesaba una etapa crítica de su formación y, por tanto, era necesario diferenciar quiénes se dedicaban a ella en forma transitoria por dicha situación y quiénes lo hacían como una ocupación permanente. ${ }^{10}$

\section{LAS PLAGAS SOCIALES}

El reclamo general fue en el sentido de emprender de inmediato una profunda reforma social entre las clases menesterosas -la cual incluía a ciertos sectores de trabjadores inactivos, a los mendigos y a los vagos. Para ello, fue indispensable la elaboración de tipologías sociales que permitieran distinguir, diferenciar y separar diversas clases de pobres y fundar instituciones de atención para cada una. ${ }^{11}$

10 Véase González Navarro, Pobreza, 1985; De Gortari Rabiela y Hernández Franyuti, Ciudad, 1989. Un buen ejemplo de esta idea fue el bando expedido el 18 de diciembre de 1851 por el gobernador del Distrito Federal Miguel M. de Azcárate: "Personas que sin tener imposibilidad fisica para proporcionarse los medios de subsistencia intentan hallarlos excitando la compasión de sus semejantes sin dedicarse a ningún trabajo $u$ ocupación útil, viviendo en una ociosidad a todas luces nociva, con perjuicio de los que realmente no pueden alimentarse sino por los auxilios ajenos."

11 La idea de reforma social estuvo presente en prácticamente todos los escritores mexicanos del siglo xIx. En general, coincidieron en señalar que ésta tenía como objetivo introducir nuevos hábitos, costumbres, actitudes que se adquirirían por medio de la instrucción pri-
El esfuerzo por diferenciar y tipificar a los pobres introdujo el criterio económico en las tipologías sociales, es decir, que el factor moral o ético fue perdiendo importancia en tanto que la sociedad moderna se abría paso. Se estableció una línea crítica entre los "pobres dignos" o clases trabajadoras y los "pobres indignos" o clases andrajosas, entre quienes estaban imposibilitados para el trabajo y quienes hacían de esa actividad un negocio.

Esa diferenciación tenía entre sus propósitos reconocer quiénes serían el eje de dicha reforma y destinar algunos establecimientos de la beneficencia pública y privada a tal fin. Para los primeros, se recomendó fueran enviados a hospitales y casas de asilo, mientras que, para los segundos, se destinaron los talleres del hospicio, las casas correcionales o, en última instancia, la cárcel, donde se les daría ocupación en actividades productivas porque era urgente "cambiarlos, moralizarlos por medio del trabajo". Por ello, la pobreza $y$, en especial, la mendicidad fueron no

maria. La capacitación para el trabajo, el ahorro, el deseo de mejoramiento social, el esfuerzo individual, los derechos y obligaciones del ciudadano fueron, entre otros, los principales valores que debían inculcarse de acuerdo con los requerimientos de una sociedad moderna, ilustrada y liberal. Lorenzo de Zavala expresó, en forma sintética, esta reforma social: "Nuestra generación ha sido transportada instantánea. mente en una especie de esfera moral distinta de aquella en que vivieron nuestros padres [...] Se advertirá que el cambio ocurrido sólo es en el orden moral más general de sentimientos e intereses y que no será sino después de mucho tiempo que se verificará en las ideas, actos y pensamientos". Véase Zavala, Ensayo, 1985, vol. II, pp. 29-289. 
sólo materia de estudio sino también de reglamentación y control. ${ }^{12}$

La reforma social que buscaba la elite política mexicana también debía comprender la reorganización de las instituciones tradicionalmente destinadas a la atención de los pobres, las cuales en su mayoría habían estado a cargo de la Iglesia católica; esto significó su secularización y el propósito de redefinir sus fines y medios para cumplir con el nuevo papel que les exigía el nuevo orden social. ${ }^{13}$

El sentido último de la reforma que perseguía la elite política era el de preservar el orden y la estabilidad social que con grandes esfuerzos se estaba edificando porque, potencialmente, se estimaba peligrosa la condición de estos grupos sociales. No es casual que uno de los más severos, pero también de los más meditados reglamentos, haya sido expedido en esa

\footnotetext{
12 El Monitor Republicano, 23 y 24 marzo 1877.

13 La tesis del nuevo orden social no fue del todo clara entre la elite política mexicana. Durante gran parte del siglo $\mathrm{xx}$ dicha noción estuvo vinculada con la presencia de la sociedad colonial, la cual se asociaba a la concentración de la tierra el predominio de la Iglesia sobre una masa ignorante y supersticiosa, el privilegio de los españoles en actividades productivas, la falta de movilidad social entre las cazas así como el dominio de los gremios sobre las más importan. tes ocupaciones industriales. Por tanto, el nuevo orden social estaría basado en el impulso de nuevas actividades lucrativas, que dotarían a los "ciudadanos" de incentivos para mejorar su situación y, por añadidura, la del conjunto de la sociedad. Así, la gran tarea era edificar un nuevo orden donde prevalecieran los principios de libertad e igualdad, la separación del Estado y de la Iglesia, la libre movilidad de la propiedad y de los individuos y la secularización de la vida social.
}

época de gran inestabilidad política. En 1865, se expidió la "Ley para corregir la vagancia", la cual retomaba el criterio económico para definirla, aunque también consideraba criterios morales con fines de control social. Vagos eran aquellos."que sin justa razón trabajan solamente la mitad o menos de los días útiles de la semana, pasando ordinariamente los restantes sin ocupación honesta".

Esta definición estableció una diferencia entre los mendigos y los vagos. Los primeros eran niños abandonados u obligados por sus padres a pedir limosna y ancianos sin posibilidades de emplearse. Para ellos había ciertas consideraciones sociales o morales, pues podían ser objeto de la be. neficencia pública o privada. En cambio, los segundos, regularmente jóvenes entre los 16 y 18 años y adultos que no podían justificar un modo honesto de vivir, en este caso limosneros, tahúres y prostitutas, fueron juzgados con mayor severidad moral y social. ${ }^{14}$

En suma, mientras que con los primeros se tendría una cierta consideración social, pues se les reservaban las casas de huérfanos o las casas de asilo según fuera el caso, los segundos serían objeto de una creciente crítica por su carácter supuestamente irredento. Para éstos la cárcel o la reclusión en establecimientos de corrección era su destino.

14 El jurista Pablo Macedo propuso ante el Congreso de la Unión, en septiembre 1880 , una iniciativa de ley que privaba de sus derechos de ciudadanos a los vagos, con el fin de evitar que éstos aumentaran en número y que estuviera permitido recluirios en establecimientos de corrección. Cámara de Diputados, Diarto de los Debates, septiembre 1880 , p. 1171. 
Posteriormente, los vagos fueron diferenciados en tres categorías, lo cual demostró un mayor conocimiento de las condiciones económicas y sociales en las que se desenvolvían: 1) los necesarios, "aquellos que no trabajan por falta absoluta de trabajo"; 2) los voluntarios, "que no trabajan porque no quieren, sin que por esto cometan acciones que dañen a la sociedad o perjudiquen a terceros", y 3) los perniciosos, "los que no sólo no trabajan, sino que cometen acciones que ofenden a la moral o perjudican a la sociedad". Estos últimos eran asiduos parroquianos de lupanares, pulquerías, vinaterías, billares y tabernas, "embriagándose u ocupados en fraguar delitos". ${ }^{15}$

En sentido estricto, no se trataba de individuos dedicados a la delincuencia sino de personas que asumían una función antisocial, antieconómica, incómoda y desagradable, y para quienes recomendaban el trabajo y la instrucción como instrumentos de moralización y símbolos del éxito y del bienestar social. Por ejemplo, en una colaboración enviada a El Monitor Republicano, se puso el acento en la "plaga de todas clases y edades de los dos sexos" para explicar que si bien la mendicidad y la vagancia no podían juzgarse como actividades criminales o ilícitas, sí predisponían a ellas en la medida en que provocaban el libre juego de la imaginación y la meditación de un crimen, y de ahí a su ejecución no había más que un paso. El colaborador sostenía que "el único antídoto especial" para prevenir tales activida-

15 Gaceta de Policta, 13 febrero 1867. des era inculcar en esos individuos el amor al trabajo porque evitaba que cayeran en cualquier tentación al tenerlos "en entretenimiento en objeto determinado". Por añadidura, la sociedad se quitaría de una preocupación constante, pues se habia demostrado que el mendigo y el vago tenían una función social muy importante en los bajos fondos de la sociedad mexicana: la de espía, encubridor de criminales o seductor de la joven y la mujer casada. ${ }^{16}$

El Estado y, en especial, los particulares, debían ser los principales promotores de dicha reforma mediante el auspicio de la beneficencia a fin de llenar el vacío social dejado por las instituciones ligadas a la Iglesia católica. La beneficencia pública y la privada fueron parte importante de la reforma al asignárseles un carácter distinto al jugado por la caridad patrocinada por la Iglesia. Cabe señalar que la reforma social no tuvo exclusivamente por protagonista al Estado ni a la elite política. Otros sectores sociales distantes de ambos centros de decisión también compartieron la idea de promoverla con el propósito de modificar hábitos, costumbres y tradiciones, pero mantuvieron importantes diferencias sobre el fin último de la reforma. Fuera de las corrientes de expresión institucional, es decir, las de los defensores del pensamiento católico, del liberal o del darwinismo social, surgieron otras de organizaciones de orientación protestante que se esforzaron por introducir una nueva mentalidad entre algunos sectores de trabajadores urba-

${ }^{16}$ El Monitor Republicano, 16 marzo 1877. 
nos y rurales, en especial, entre los maestros normalistas y los pequeños propietarios rurales que, como sectores emergentes y poco favorecidos por el crecimiento económico, buscaban un nuevo espacio de acción social, política y religiosa que les dotara de identidad y que rompiera con el control social que se ejercía sobre ellos. Aunque de menor influencia numérica, estas organizaciones forjaron un ideal de hombre ascético y activo, promotor de la individualidad como eje de la sociedad y el Estado moderno y capaz de sostener relaciones igualitarias con el Estado e impulsar nuevas relaciones entre los grupos sociales. Este ideal encontró, en determinadas circunstancias, similitudes con los propósitos de reforma de la elite, pero paradójicamente, y conforme avanzaba en influencia social y geográfica, fue enfrentando obstáculos en su acción. El distanciamiento entre los objetivos de la elite y los de estas organizaciones protestantes, llevaría a éstas últimas a criticar la acción del Estado por considerar que favorecía los intereses de la elite y de la Iglesia católica, así como a montar una red de influencia considerable al fundar escuelas, talleres y otro tipo de instituciones donde se inculcaba el modelo de hombre que deseaban forjar. ${ }^{17}$

\section{LA POBREZA A DEBATE}

Al mismo tiempo, durante el siglo XIX y en particular durante el porfiriato una nueva idea de la pobreza y de los pobres originó, entre otras cosas,

17 Véase Bastian, Distdentes, 1989. una polémica entre quienes sostenían la tradicional doctrina de la pobreza y los promotores de la secularización de ésta. Uno de los temas más candentes fue el papel que la caridad y la beneficencia jugaban en la reforma social.

Según el periódico progobiernista El Imparcial, la caridad católica fomentaba la mendicidad, la vagancia y los vicios, mientras que la reforma social, practicada por el gobierno y algunos particulares, promovía la virtud y el trabajo. Asimismo, algunos defensores de la caridad afirmaban que, en el fondo de la filantropía, existía un motivo de presunción y dudaban de una verdadera vocación humanitaria. ${ }^{18}$

En este mismo siglo surgió una generación de reformadores, tanto religiosos como filántropos, que propusieron una serie de mejoras allí donde juzgaron que eran inaplazables. Este esfuerzo reformista iba acompañado de una nueva concepción del modelo y del tipo de hombre que debía forjarse en esos establecimientos, des-

18 Un debate similar ocurrio entre otros países en torno al papel de la caridad y la beneficencia. En Italia, a fines del siglo xvil se discutió en relación con el destino de los fondos de caridad. El criterio que prevaleció fue que en ninguna circunstancia la limosna podla oriencarse a "aumentar el pueblo de los perezosos" o de quienes se dedicaban a simular su condición de pobres, sino a crear en ellos el placer por el trabajo, a convertirlos en hombres "industriosos y amantes de la fatiga", así como a "corregir y mejorar sus costumbres". Por ello se demandaba la creación de hospicios públicos donde se les proporcionara alimentación y vestido a cambio de "obligar a todo el que puede al ejercicio de sus fuerzas en trabajos continuos". Este tipo de instituciones serían "la medicina universal capaz de hacer concordar la ley del santo amor al prójino con la del sabio gobierno político". Véase Mellosi y Pavarini, Cárcel, 1980, pp. 110-114. 
pués de tener la certidumbre de su regeneración. Trabajo, educación, religión y amor serían la base de la metamorfosis social e individual que los sacaría de la degradación, la miseria y el vicio.

LA REFORMA SOCIAL: ORDEN, HONESTIDAD Y VIRTUD

Las reformadores sociales estaban convencidos, en una visión optimista del progreso y la civilización como fuentes de redención social, de poder modificar algunos atavismos culturales o biológicos y de poder persuadir a los pobres para que soportaran su situación, abandonaran su vida de disipación o criminalidad y aprendieran a valorar las virtudes y habilidades del trabajo honesto para hacerse mejores hombres. El resultado sería un hom. bre nuevo. De sus establecimientos saldría "un ser moral" con nociones del bien "ensanchando en este efecto los límites de la inteligencia y los buenos sentimientos del corazón".

Se intentaba diseñar un modelo de hombre que tenía mucha similitud con el ideal del hombre protestante, puritano, que respondiera a los "hombres ilustrados" en quienes el trabajo y estudio fueran las bases de su formación, que se convirtieran en hombres dignos en el taller, la cátedra o la tribuna y que tuvieran como recompensa el bienestar personal. Este prototipo de individuo sería bien apreciado y destacarían en él las ventajas de la abstención del consumo de alcohol, de tabaco, del trabajo dominical y de los juegos de azar así como su condena al libertinaje sexual y la importancia otorgada al matrimonio civil.
Todos estos comportamientos de rechazo a los valores tradicionales y populares llevaron a la formación del tipo de trabajadores necesarios para la fábrica y el trabajo moderno y a la creación de una mentalidad popular ascética. ${ }^{19}$

En contraste con estos reformadores, hubo quienes sostenían que la simple idea de la redención social era una utopía. Justo Sierra y Francisco G. Cosmes, prominentes miembros del periódico liberal moderado La Libertad y activos difusores del organicismo en el país, consideraron que cualquier proyecto de reforma en este sentido estaba destinado al fracaso. El propósito de tal reforma institucional que promovía el Estado porfiriano era, según ellos, un legado de la utopía liberal, por lo menos hasta que la sociedad mexicana hubiera alcanzado cierto grado de desarrollo material que elevara a los pobres a un grado de cultura y aprendizaje superiores. En su opinión, las cárceles debían ser sitios de intimidación y represión, instituciones destinadas al castigo severo contra quienes habian atentado contra el orden y las leyes sociales. ${ }^{20}$

No había más cura que la pena de muerte ni más corrección que las penas extremas y los castigos más severos. Escépticos, no creían en la regeneración de las costumbres ni en las actițudes innatas de los delincuentes. Para esos antirreformistas, más que principios abstractos se requería mantener la paz social, y era preferible ceder todos los derechos individuales antes que permitir el desorden social y la

19 Bastian, "Metodismo", 1983, pp. 39-71.

20 Sierra, Obras, 1948, vol. Iv, pp. 358-361. 
anarquía: ni utopía ni reformas carcelarias podían suprimir la criminalidad. Según Sierra, era la ley fatal de la conservación la que imponía este deber. Ser severo era ser justo, sentenció. ${ }^{21}$

Sin duda los juicios de estos pensadores no eran compartidos por la gran mayoría de las autoridades del país ni menos aún por los promotores de la reorganización institucional y de la reforma social, entre otras cosas, porque dichos procesos de renovación se habían forjado lentamente. Entre los promotores de esta reforma existía la certeza de la rehabilitación y regeneración de los trabajadores y, por añadidura, en su conversión en miembros útiles de la sociedad. ${ }^{22}$

\section{LOS FINES DE LA REORGANIZACIÓN INSTTTUCIONAL}

Uno de los más activos difusores de la

21 Ibid.

22 Conviene a estas alturas comparar la experiencia de nuestro país con uno de los países pioneros en la formación de este tipo de instituciones: Inglaterra. Aquí, el proceso de estudio de los pobres se vio acompañado por la fun. dación y promoción de sociedades filantrópicas que poca relación tenían con el Estado. En cambio, en México las leyes de reforma provocaron que la Iglesia católica dejara un vacío social de instituciones orientadas a asistir a los pobres. En esas circunstancias, a las cuales se sumaba la carencia de experiencias similares a la inglesa, es decir de iniciativas individuales, voluntarias y creadas por diferentes sectores de pobres y no corporativas como las patrocinadas por la Iglesia, el Estado mexicano se encargo de reorganizar casi todo el aparato institucional de atención a los pobres y de reglamentar la beneficencia privada, siempre bajo su supervisión con objeto de impedir que de nueva cuenta se concentrara en manos del clero. Himmerlarf, Idea, 1988, pp. 357-468. reforma social, José María Castillo Velasco, a la sazón presidente del Tribunal Superior de Justicia del Distrito Federal, estaba plenamente convencido de que dicha reforma tenía que procurar una renovación de las costumbres y hábitos, haciendo de la moralización y la instrucción el eje de la misma. Al presentar un informe al Congreso de la Unión sobre su propuesta destacó que el mayor número de presos y encausados pertenecían a la "clase ínfima del pueblo", quienes carecían de arte, oficio y educación. Entre ellos sobresalían peones de todas clases y jornaleros del campo. Después les seguían los ocupados en oficios y artes "que no exigen el desarrollo de una gran fuerza muscular, sino un trabajo sedentario": zapateros, sastres, tejedores y otros. En un grado superior en la escala de la criminalidad se hallaban los carpinteros y curtidores y, ocasionalmente, "los hombres que se ocupan de ciertas labores que los ponen en contacto con clases de la sociedad, superiores en educación": plateros, ebanistas, impresores y cajistas. Para Castillo Velasco, el factor fundamental de las conductas antisociales residía en la falta de instrucción y educación, más que en factores económicos o sociales, porque aquéllas enseñaban a "dominar las pasiones". Por ello urgió a las autoridades a "llevar los beneficios de la educación a esos desgraciados jornaleros y a todas las clases de la sociedad que carecen de ella". Una clase aparte eran los indígenas, quienes también carecían de instrucción, pero el indice de criminalidad entre ellos era menor porque "diariamente agotan sus 
fuerzas en el trabajo y tienen menos ocasión de delinquir". La educación que les fuese impartida tendría otro tipo de beneficios en tanto que les mostraría las ventajas de la producción y el consumo de lo nacional. En fin, la escuela inculcaría entre las clases menesterosas "nuevos hábitos, nuevas necesidades, nuevas costumbres" $y$ evitaría "en ciertas esferas de la sociedad muchos delitos, en particular los robos". 23

Por su parte, un lector de La Libertad opinó que la educación tenía el propósito de "hacer aptos a los individuos para la vida completa", es decir, entre los jóvenes se inculcarían los valores del bien y del mal enfrentándolos con sus propias experiencias. El efecto pedagógico se demostraría cuando dichos jóvenes encontraran en su espíritu la noción justa del bien y del mal y, en materia de conducta, cuando aprendieran a reconocer las malas acciones, que les conducirían a comprender que la justicia significaba penalidad, y no porque fuera una invención de los individuos, sino porque la naturaleza tenía sus propios correctivos para enmendar las conductas torcidas. Con ello la socie-

23 El Monitor Republicano, 23 y 24 mayo y 28 julio 1877. En opinión de Mellosi y Pavarini, el móvil principal de la fundación de los establecimientos de beneficencia, en particular los orientados a funciones pedagógicas y reeducativas, fue sostener una tendencia a recuperar $y$ reeducar a los niffos y jóvenes, en especial éstos últimos, por ser fácilmente corregibles, dóciles y resistentes para incorporarse al mundo del trabajo. Ello explica por qué las casas correccionales fueron acompañadas de escuelas profesionales, orfanatorios, etc. Mellosi y Pavarini, Carcel, 1980 , pp. 100-101. dad se beneficiaria, contribuyendo la instrucción a la estabilidad social y al bienestar de los hombres. ${ }^{24}$

\section{El APARATO INSTTTUCIONAL: BENEFICENCIA PÚBLICA Y PRIVADA}

La diferenciación de los pobres creó también una distinción entre las instituciones destinadas a su atención con distintos medios y fines. Unas se destinaron a la prevención de las conductas antisociales, entre ellas la prostitución, la vagancia y la mendicidad, en tanto que otras lo eran a reprimir las conductas ilícitas o criminales. Las primeras quedaron a cargo de la beneficencia pública y privada y las segundas se reservaron a la vigilancia estatal, en particular las instituciones carcelarias y correccionales. Ambas tendrían por objeto central el control social y la educación a fín de evitar los efectos más indeseables de ambas conductas.

Las primeras orientarian su labor hacia las "clases más desprotegidas"; con ello se prevenía lo que tanto temía la elite gobernante, al cerrar el círculo de su lógica con esos institutos: la pobreza como posibilidad de acciones antisociales, que podian poner en peligro el orden social y, por ende, la necesidad de construir sitios que mitigaran la conflictividad social, regularan los conflictos y tensiones del crecimiento económico y, finalmente, forjaran un nuevo hombre.

Entre sus finalidades estaban hacer hombres útiles sin hacerlos sentir que se les confinaba, y crear talleres con

${ }^{24}$ La Libertad, 15 enero 1879. 
la obligación de restituir a la sociedad el costo de su capacitación y estancia, pues la existencia de esas instituciones no debía juzgarse como concesión gratuita porque la experiencia había demostrado que cuando la caridad, la filantropía y la beneficencia se ofrecía sin ningún compromiso, se fomentaba la ociosidad y la holgazanería. ${ }^{25}$

Uno de los estudios más acuciosos en este campo fue el presentado por Justino Fernández Castelló. Para este autor, la pobreza tenía diferentes motivos y causas. Por ello era indispensable analizarla para, a su vez, formular diversos medios de prevención y alivio. Esos motivos o causas podían ser por completo ajenas a la voluntad de los individuos: epidemias, inundaciones, despidos y otros elementos eran ajenos a cualquier cálculo. Criticaba a aquellos que pensaban que la pobreza y la miseria se reducía a una "falta de espíritu de previsión" o que eran las leyes naturales las que hacían aptos o ineptos a los hombres. Sin embargo, no negaba la desigualdad social, pero un hecho era admitirla y otra muy distinta sostener "el bárbaro principio de la selección", el cual eliminaba a los pobres, a los niños, a los ancianos, a los enfermos y, por ende, desconocía los sentimientos humanitarios. ${ }^{26}$

La "beneficencia científica" era por tanto útil, necesaria e imprescindible para esos casos. Esa beneficencia reconocía cuatro niveles de pobreza: 1) Aquella cuyo origen fuera el nacimiento o un accidente: ser sordo-

25 García Icazbalceta, Informe, 1907.

26 Fernández Castello, Fundaciones, 1897, pp. $13-70$. mudo, ciego, paralítico o haber sufrido el deceso del jefe de familia. 2) La de quienes padecían condiciones sociales adversas, "casos pasajeros que son la consecuencia de ciertos cambios generales verificados en el seno industrial de una sociedad", como los desplazados por la introducción de tecnología y de modificaciones en la división del trabajo. La ayuda que se brindaría a éstos tendría un carácter perentorio y sería un complemento de la previsión, es decir cajas de ahorro, sociedades mutualistas y cooperativas. 3) La de las víctimas de las costumbres y los vicios de sus padres, quienes fomentaban su mendicidad como un medio de lucro, así como la vagancia. Estos últimos formaban el contingente del "pauperismo, es decir la miseria hereditaria". La beneficencia se cuidaría de no promover el vicio y la degradación social y "arrancarlos del foco degradante y envilecedor en que viven", en especial los niños. 4) Este nivel lo integraban aquellos "débiles morales o intelectuales" que eran producto de sus vicios, de la imprevisión, de la vagancia, de la glotonería y del alcoholismo. Para ese sector la beneficencia no tenía ninguna obligación porque ponía "un freno al vicio fomentando, a su vez, el sentido de previsión". El tratamiento adecuado y juicioso en cada uno de esos niveles permitiría al Estado y a la sociedad guardarse de quienes juzgaran que su situación era resultado de la dureza de la sociedad y evitaria "que adoptaran la teoría de que era necesa. rio un cambio en el orden social", ${ }^{27}$

27 Ibid., González Navarro, Historia, 1957, vol. Iv, p. 518 . Entre ambas posiciones había una serie de matices. Por ejemplo, hubo quienes reconocían la importancia de la beneficencia 
En resumen, la función de esas instituciones era prevenir los crímenes y evitar la proliferación de los delincuentes. Mediante la disciplina y el trabajo se procuraría que los inquilinos "comprendan que [en] nuestra época es difícil abrirse paso cuando no se lleva un caudal de conocimientos para vencer las dificultades que a menudo impiden la marcha del hombre", asi como "modificar el carácter, evitar los extravios y perderse en pasiones insanas". ${ }^{28}$

\section{EN BÚSQUEDA DE LOS POBRES $Y$ DE LOS CRIMINALES}

Proceder de esa manera significaba conocerlos e identificarlos dentro de sus propios espacios sociales de convivencia o donde realizaban sus actividades. Era necesario vigilarlos. Esa tarea no fue fácil y llevó un poco de tiempo. Un primer paso fue reglamentar una serie de medidas de vigilancia; se empezó, entre otras cosas, con el esfuerzo de sistematizar la información que se tenia a la mano (en especial, las estadísticas de criminalidad que incluían a las personas dedicadas a la mendicidad, a la vagancia o a las actividades delictivas) y con la puesta en práctica

pero criticaban la excesiva intervención del Estado en este punto. Sostenían, en el más puro estilo liberal de la época, que no era ni atribución ni obligación estatal intervenir en un campo reservado exclusivamente a los particulares. En todo caso, el Estado tenía la facultad de reglamentar la organización y el funcionamiento de los establecimientos de beneficencia. Este era el punto de vista del jurista Miguel Macedo.

${ }^{28}$ Peza, Beneficencia, 1881, pp. 165-166. de la reorganización policiaca; ambas tuvieron consecuencias notorias entre los pobres. ${ }^{29}$

Este proceso fue lento y desigual. En 1825, el Congreso general dispuso la formación de un cuerpo de polícia municipal para la ciudad de México con el nombre de "celadores públicos", el cual sustituyó a los antiguos "serenos". El 2 de marzo de 1861, se sentaron las bases definitivas con una ley que regulaba el funcionamiento y la integración de la policía $y$, en 1864, se ejecutaron las disposiciones que contenía dicha ley. Para ello se dividió la capital de la república en 9 cuarteles y éstos quedaron al mando de un comisario central. Posteriormente, en 1873, se creó la Inspección General de Policía con la misión de "prevenir los delitos y perseguir a los infractores", en especial a los asiduos concurrentes a las casas de juego. ${ }^{30}$

Las funciones de policía, es decir de vigilancia y control, cubrían un amplio espectro de actividades: desde el resguardo de cárceles, hospitales y rete-

29 El proposito fundamental de la reorganización policiaca fue prevenir y reprimir las nuevas formas de criminalidad que aparecieron durante el siglo $\mathrm{xx}$. Sin embargo, este proceso alcanzó su mayor auge durante el porfiriato. La urgencia de presentar una imagen de estabilidad política y social, que justificara ante la elite política y los inversionistas extranjeros las bondades de un régimen autoritario y dispuesto a imponer el orden, llevó a Porfirio Díaz a introducir políticas más eficaces para contener la criminalidad, tales como la edificación de la penitenciaría del Distrito Federal, la organización y profesionalización de los cuerpos policiacos, la reorganización de los tribunales federales, las reformas y adiciones al código penal y la supresion de facultades a los jurados populares.

30 Novo, Año, 1973. 
nes hasta el cuidado de calzadas y de reos en traslado, pasando por labores de sanidad y de higiene pública, vigilancia del alumbrado, mantenimiento del orden público en diversiones y bailes públicos $\mathrm{y}$, finalmente, la persecución de vagos y malhechores. ${ }^{31}$

Fue hasta las sucesivas administraciones de Porfirio Díaz cuando se logró un mayor grado de profesionalismo en la policía mexicana, aunque no faltaron las quejas, en especial de los periódicos, acerca de la incapacidad policiaca para cumplir con sus obligaciones. Así pues, los resultados fueron muy desiguales. Según $L a G a$ ceta de Policía se había dado un gran paso en el ramo de policía desde los primeros años de gobierno de Porfirio Díaz, aunque admitía que la estadísitica criminal resultaba "fatídica" por el alto número de consignados a las autoridades. Por ello, se preguntaba hasta dónde el índice de criminalidad demostraba la eficacia policial, si no para prevenir el crimen sí para su represión, o bien si efectivamente había aumentado la delincuencia. Juzgaba que había un problema de sociología para el bufete de todos los hombres de Estado, es decir, tenían la responsabilidad de responder a varias preguntas: “En la capital de la república se incrementa la criminalidad? ¿Este crecimiento es en realidad alarmante?" La respuesta había que buscarla en otra parte: en el crecimiento de la población que de todas partes del país llegaba a la ciudad. Ahí residía "el secreto de una alarma que tiene más de efectista que de fundada" y pregun-

31 Tiburcio Montiel citado en Novo, Año, 1973; Santoni, Policta, 1983, pp. 97-129. taba, en tono desafiante: "¿Hay entre nosotros criminalistas capaces de entregarse a este trabajo?"32

Por otra parte, la reforma policiaca provocó situaciones en las que los abusos y equivocaciones fueron en perjuicio de quienes la padecieron. Por ejemplo, era frecuente que personas procedentes de las inmediaciones de la capital fueran detenidas, acusadas de vagancia y trasladadas a la cárcel de la ciudad. Mientras se comprobaban los datos proporcionados por el detenido, las autoridades lo mantenían encerrado por días o meses. Para muchos de ellos, significaba que sus familiares padecieran el abandono de los "hombres laboriosos", del único sostén familiar en muchos casos. ${ }^{33}$ En una muestra de 100 casos, remitidos entre 1864 y 1865 al Tribunal de Vagos, se concluyó que $93 \%$ de los inculpados manifestaron tener un oficio o empleo temporal y sólo $7 \%$ restante declaró carecer de oficio alguno; este grupo lo integraban los menores de 16 años. Por tanto, estamos hablando de una masa de población de artesanos y trabajadores que enfrentaron situaciones de crisis por falta de empleo. ${ }^{34}$

No obstante, no faltaron algunos éxitos para las autoridades. Hubo casos en que los detenidos, habiendo sido sorprendidos en "actitud sospechosa", confesaron dedicarse a las "suertes" o a "la industria que consiste

32 La Gaceta de Policia. Semanario Ilustrado, 8 y 21 octubre: 10 diciembre 1905.

33 Archivo Historico de la Ciudad de México (AHCM), Vagos, exp. 428, 515 (1867); El Globo, 2, 14, 15 y 17 agosto; 19 septiembre 1895 .

34 Mendoza Ramírez, Presos, 1989, pp. 95100 . 
en bailar muñecos con un pelo", es decir, a la vagancia completa. El destino provisional de los confesos dependió, en gran medicla, de la edad que tuvieran. Entre ellos se encontraban niños huérfanos y adolescentes o jóvenes que habían huído de la casa paterna, así como personas de edad avanzada. Para los primeros estaban reservadas las casas de niños expósitos, las escuelas correccionales o las industriales con el fin de proveerlos de algún oficio e instrucción, mientras que para los segundos estaban las ca. sas de asilo o los hospitales. Para los adultos, cuya edad fluctuara entre los 16 y los 54 años, los trabajos forzados, las tareas de limpia o la leva. ${ }^{35}$ Finalmente, la cárcel si se demostraba su peligrosidad o se comprobaba que el detenido era reincidente en delitos menores. ${ }^{36}$

\section{LAS PROPUESTAS DE REFORMA INSTITUCIONAL.}

Al iniciarse el porfiriato, tanto las instituciones dedicadas a la prevención como las dedicadas a la represión de las conductas antisociales y criminales, se encontraban en un estado que causaba espanto y repugnancia a quienes las visitaban, al igual que el provocado por las "cuadrillas de léperos sucios y perdidas greñudas" o los batallones de pedigüeños en cafés, teatros, calles $y$ templos, formando la "cofradía inmoral de la limosna callejera". ${ }^{37}$

El conocimiento de los habitantes

35 González Navarro, Anatomía, 1977, pp. 176-195.

36 АнСм, Vagos, exps. 428, 515, 540 (1867).

37 Urbina, Cronicas, 1946, pp. 19-20. de aquellas instituciones pronto reveló una realidad más dramática $e$ inhumana que los prejuicios sociales y morales: la del trato inhumano que les dispensaban los encargados de las cárceles, asilos, hospitales, escuelas de artes y oficios, escuelas industriales, hospicios, etcétera. La tarea que se echaron a cuestas fue prácticamente irresoluble:

Cada reforma era una respuesta a un problema que pedía a gritos una reforma; cada expresión de compasión y cada reacción eran provocadas por una evidencia inequívoca de miseria y vicio. ${ }^{38}$

Las cárceles y las prisiones, así como los huéspedes en ellas alojados de-

38 Himmerlarf, Idea, 1988, p. 324. En 1871 Antonio Martínez de Castro, responsable de la comisión encargada de elaborar el código Penal para el Distrito y Territorios Federales, primero en su especie en México, resumió la situación lamentable de las cárceles del Distrito Federal: "En ellas se ven aglomerados, confundidos y en completa comunicación personas de todas las edades: el ladrón ratero y el salteador en cuadrilla, el reo de simple rína y el asesino, el hombre honrado que, en un momento de pasión o ceguedad, cometio una ligera falta, $y$ el fascineroso, los criminales ya condenados y los inocentes a quienes se está procesando. Entregados todos ellos a una absoluta ociosidad, son actores o testigos de las escenas más vergonzosas y repugnantes, y no se escuchan sino el relato de espantosos crímenes, o los planes y proyectos de otros nuevos. Allí no hay más títulos a la consideración que la desvergüenza, el derecho, la osadía; $y$ aquellas turbas de malvados se complacen en hacer víctimas de su brutalidad, y en arrancar todo sentimiento de honor y de virtud a los que no están corrompidos como ellos." Martínez de Castro, "Exposición", 1868, p. 152. 
mostraron la profundidad de la reforma que debía emprenderse. Sin embargo, los reformadores enfrentaban un efecto indeseable cuando emprendian o promovian las reformas en esas instituciones: cómo disuadir a quienes se dedicaban a delinquir en que mudaran su forma de vida por el trabajo honrado; cómo inducir al indigente a aprovechar las ventajas de la ayuda y el trabajo; al preso, a cambiar el placer de una vida cómoda donde tenía garantizados la comida y el sustento pero donde representaba una carga para su familia, por las penalidades del trabajo regular y honrado. Había pues, que evitar que las condiciones de los huéspedes de los establecimientos de beneficencia y carcelarios fueran preferibles a las de las clases trabajadoras. ${ }^{39}$

La reforma institucional y social venía precedida por significativos intentos de ajustar las instituciones a las nuevas condiciones del país. Los pro-

39 Las autoridades de la ciudad de México estaban conscientes de este inconveniente. En 1873, el gobernador del Distrito Federal, Tiburcio Montiel, sostenía que la alimentación que recibían los presos de las cárceles de la entidad eran de mucho mejor calidad que la que consumía el vecindario y agregaba que, en general, la estancia en esos sitios no era tan mala, "sobre todo si se tiene en cuenta la vida miserable del pueblo en general, pues en la calle no come sino tortillas y casi nunca carne". Asimismo, en 1881, el entonces gobernador del Distrito Federal Ramón Fernández advirtió que la cárcel debía considerar un sistema de castigo riguroso para evitar "que el establecimiento [sea] un lugar atractivo o de tentación, un refugio atractivo e irresistible". Memoria del Ayuntamiento, 1878; Montiel, citado en Novo, Año, 1973; Diario Oficial, núm. 196, 18 agosto 1881 . motores ya contaban a esas alturas con suficientes experiencias para promoverla. El impulso definitivo se produjo bajo las administraciones de Porfirio Díaz, en las cuales se recopilaron suficientes antecedetes sobre ideas y modelos de atención social a los pobres que se habian intentado, sin éxito, en diversas épocas en el pais.

Además, en este periodo se dieron las condiciones más propicias para ello: el país había entrado en un etapa de relativa estabilidad política, con la presencia de una institución capaz de asumir como una de sus obligaciones la atención y el cuidado de las prisiones mexicanas, en la medida en que éstas eran uno de los mecanismos para garantizar el orden y la seguridad. En suma, el Estado porfirista estaba comprometido a reorganizar el conjunto de los aparatos de control social.

Sin embargo, se mantuvo cierto escepticismo entre quienes intentaban participar en forma activa en el terreno de la beneficencia. Por ejemplo, Miguel Macedo sostuvo que una de las consecuencias más graves de la reforma había sido la de despertar el temor y la desconfianza entre los particulares para fundar establecimientos filantrópicos debido a la falta de leyes en esta materia, lo cual les impedía cumplir con sus deseos. En efecto, el temor de los filántropos era real, pero no sólo por la falta de disposiciones efectivas y claras, sino también porque muchos de ellos habían sostenido largos litigios para lograr que les fueran devueltos sus fondos de caridad y que pocas veces les favorecian. Asimismo, el Estado tenía sus reservas respecto 
a permitir la libre organización y participación de particulares en la administración de este tipo de instituciones, sobre todo porque en varias ocasiones se habían presentado denuncias en contra de los encargados de esas instituciones a causa de los malos manejos en los escasos recursos que administraban. ${ }^{40}$

Mientras tanto, y en forma paralela, se promovió la reforma penitenciaria como parte de un proceso de mayor amplitud que incluía asilos, casas de correción, escuelas de artes y oficios, casas de expósitos y en general las instituciones de beneficencia. Las instituciones de control social se diseñaron para mitigar los efectos que provocaban los desjustes económicos y sociales del "industrialismo" entre grandes sectores de la población y que se re. flejaban en un incremento de la vagancia, la mendicidad y la delincuencia. Esos establecimientos fueron concebidos como centros de enseñanza fabril y de aprendizaje de nuevos hábitos, costumbres, actitudes y conductas más acordes con las necesidades de una economía en expansión. En ellos se inculcaría la disciplina, el orden y el respeto a la propiedad privada. En una palabra, para forjar un trabajador ideal, se corregirían sus conductas calificadas de antisociales y se le capacitaría para el trabajo. Los promotores de la reforma penitenciaria consideraban necesaria y posible la creación de espacios de segregación donde pu-

40 Archivo Histórico de la Secretaría de Salud (AHSs), Fondo Beneficencia Pública, Sección Dirección General; González Navarro, Pobreza, 1985, p. 499; Secretaría de Gobernación, Beneficencia, 1899. diera forjarse un hombre nuevo con cualidades tales como el amor al trabajo, la honradez y la instrucción.

En general, la edificación de un completo sistema de control y atención social a los pobres tuvo la finalidad de establecer las distintas funciones de los establecimientos de correción y de beneficencia: cuando las instituciones preventivas no pudieran impedir la violación de las leyes sociales, entrarían en acción los establecimientos de castigo, represión y corrección. Para los remisos no serían suficientes las instituciones preventivas, sino las intimidatorias y represivas con el fin de enderezar sus conductas. Las cárceles y penitenciarias seguirían una pauta similar de organización y funcionamiento, aunque la diferencia básica sería la privación de la libertad y la segregación total. Esos establecimientos fueron proyectados como el modelo de institución de control social.

Así se sistematizó un método de premios y castigos, se suprimieron formalmente los castigos físicos y el régimen de inspección y vigilancia se hizo más sutil, "a fin de que el preso no tenga jamás la seguridad de no estar vigilado o de no poder ser sorprendido". La observación se personalizó ordenándose un control riguroso, lo cual se completaba con la enseñanza religiosa al cuidado de sacerdotes reconocidos y "bien conceptuados" y con la instrucción y la capacitación laboral. ${ }^{41}$ Según los reformadores, su propuesta no provenía de inspi-

${ }^{41} \mathrm{AHCM}$, Cárceles, vol. 501, exp. 707 (1878); 696, 1876; vol. 502, exp. 701 (1880); Romero, Sistema, 1897. 
raciones metafisicas o de especulaciones. Su modelo carcelario tenía su referente en el funcionamento y organización de la sociedad:

La semejanza de la constitución de la penitenciaría con la de la sociedad, debe enseñar al preso que en ésta lo mismo que en aquélla, el medio de obtener el bienestar y la felicidad es la honradez, y que el camino del vicio lleva al dolor $y$ termina en el infortunio. Inculcar esta idea en el preso, hacer que en su espíritu se reestablezca una robusta y firme asociación es el medio más eficaz para hacerle adoptar el buen camino. ${ }^{42}$

El estado de abandono de los establecimientos de beneficencia y corrección era una dramática realidad. Los edificios se encontraban en pésimas condiciones materiales y quienes se aventuraban a sufrir esos espacios, habitaban galerías inmundas, padecían los efectos de la aglomeración y el consiguiente riesgo de contraer o provocar epidemias que los diezmaban, todo ello en un ambiente de corrupción y desorganización administrativas que favorecía el deterioro de sus condiciones de vida. Pero eso no impidió propuestas de soluciones al problema procedentes de empresarios y filántropos que mostraban preocupación por dichas instituciones.

El tema de la reforma institucional y social, los obstáculos, las condiciones de los edificios y de los huéspedes, la falta de recursos para financiar los tra-

42 Boletín del Archivo General de la Nación, 1981-1982, núms. 1-4, p. 26. bajos que exigían la construcción de edificios modernos y funcionales, las consecuencias de las continuas asonadas y el empleo de los reos como fuerza militar fueron punto de reflexión para algunos gobernantes, quienes veían en él el reflejo de los males del país; asimismo la urgencia de repensarlo sobre nuevas bases, es decir sobre la estabilidad política y el crecimiento económico "en orden y progreso". También se manifestaba una inquietud más profunda y que tenía relación con la idea del tránsito de la barbarie a la civilización. ${ }^{43}$

En particular, la reorganización penitenciaria atrajo la atención de algunos escritores de la época. En 1844, el escritor y político jaliscience Mariano Otero afirmó que la "legislación criminal, es a la vez el fundamento y la prueba de las instituciones sociales". Las cárceles eran un signo de los tiem. pos, de los viejos y de los nuevos, en que se había formado la nación. En ese sentido, desde los primeros empeños realizados por el patrocinador cultural Manuel Eduardo Gorostiza, fundador en 1843 de la Casa de Corrección para Jóvenes Delincuentes, hasta los esfuerzos del ingeniero Antonio Medina y Ormaechea y del primer director de la Penitenciaria del Distrito Federal Miguel Macedo, las iniciativas sobre la renovación carcelaria vinieron de particulares. Tampoco faltaron planes sugerentes e imaginativos de altruistas, empresarios y comerciantes para brindar recursos con objeto de financiar la edificación de penitenciarías a cambio de concesiones federales de distinta

13 Macedo, Municipio, 1902, vol. 1, vol. 2, pp. 665-724. 
índole, pero la ausencia de una organización estatal descentralizada, el permanente cambio de administraciones y los sucesivos regímenes políticos pronto desalentaron esas iniciativas debido al peligro de perder las prebendas gubernamentales. ${ }^{44}$

El resultado fue el deterioro gradual de las prisiones y su poca fortuna. Por ello, el siglo xIx fue un periodo de experimentación y maduración del régimen penitenciario y concluyó con el porfiriato. El arribo al poder de Porfirio Díaz y la administración de Manuel González, fue el lapso en que se sentaron en definitiva las bases de la reforma carcelaria mexicana, significó el fin de los esfuerzos individuales y determinó que el Estado asumiera el proyecto penitenciario como una de sus tareas fundamentales, así como una respuesta a la necesidad de la reforma penal que demandaban los sectores ricos y la elite gobernante.

En la década de los cuarenta del siglo pasado varios intentos de reforma carcelaria se efectuaron. La cárcel de la ex Acordada, suprimida por las Cortes de Cádiz en 1812, se hizo célebre no sólo por el temor que inspiró entre sus habitantes, sino por las constantes denuncias de los intelectuales de la época que, por distintos motivos, se hospedaron en ella, o porque su inclinación a tratar este tipo de temas originó importantes reflexiones sobre la necesidad de fundar el régimen penitenciario. Entre éstos, destacaron el escritor y periodista Manuel Orozco y Berra, Manuel Payno y Mariano Otero. 45

44 Ibid.

4 El Mosaico Mexicano, 15 febrero 1844.
Este último realizó una profunda y meditada disertación sobre las condiciones materiales y humanas de tal sistema de confinamiento. A Otero le corresponde el mérito de haber propuesto en forma ordenada el sistema penitenciario $y$, tras de una larga reflexión, se pronunció en favor del modelo a plicado en la prisión norteamericana de Filadelfia, con el cual fue bautizado. El autor consideró la instau. ración de la penitenciaría como una contribución fundamental a la reforma social que la nación demandaba. ${ }^{46}$

Tanto Otero como Orozco y Berra denunciaron que la situación de las cárceles debía provocar vergüenza y repugnancia entre la sociedad mexicana, aunque el segundo se inclinó por el sistema Auburn porque se le consideraba como más adecuado para la realidad del país debido a la organización carcelaria del trabajo que se establecía mediante la creación de talleres, adaptados a la organización artesanal del país. ${ }^{47}$

46 Otero, Obras, 1959. El sistema penitenciario de Filadelfia, instituido en 1790 , se estructura conforme al aislamiento celular e individual de los reclusos con la obligación de guardar silencio, incomunicado a fin de meditar sus actos. Asimismo, prescribe la oración obligatoria. El diseño y funcionamiento se basaba en la idea de separar al reo y evitar el contacto con sus ve. cinos para evitar la promiscuidad e inhibir el factor criminogeno. Según estos principios, se inducía al reo a entrar en un proceso de introspección que se juzgaba el vehículo más eficaz para su regeneración. Mellosi y Pavarini, Cárcel, 1980 , pp. 170-172.

17 El sistema de Auburn funcionaba bajo otros principios: confinamiento solitario por la noche y trabajo común durante el día, con la obligación de mantener el silencio entre los reos. Según Pavarini, la introducción del trabajo 


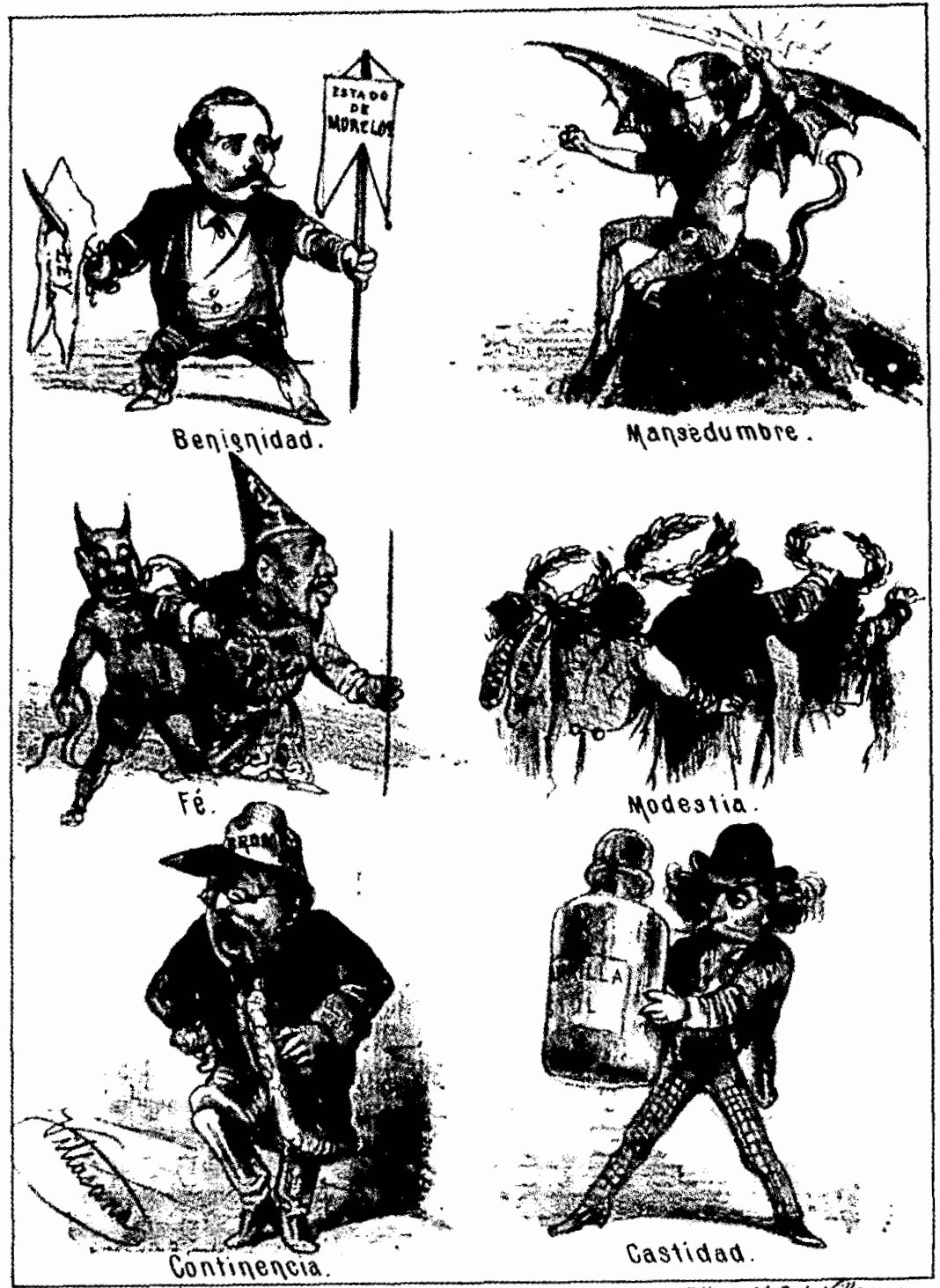

Codiror: M. C.dorilleqas.

Los frutos del "Espiritu" de la época. 
Para Otero, el sistema penitenciario era la "adquisición más preciosa" de las instituciones modernas, que consistia en "la soledad que hace reflexionar, en el trabajo que doma las malas inclinaciones, en el aislamiento que preserva, en la instrucción que eleva, en la religión que moraliza y en el arre. pentimiento que regenera". Para ambos autores la prisión de la ex Acordada degradaba y envilecía al hombre "más por la manera de tratarlos que por sus crímenes".

En 1842, el primer esbozo de régimen penitenciario se formaliź con la fundación de la Casa de Correción para Jóvenes Delincuentes. Para Antonio Medina y Ormaechea dicho establecimiento fue el "primer germen de esa hermosa institución" en nuestro país. Otero destacó la labor de su promotor y filántropo José Gorostiza, pero la juzgó insuficiente debido a la carencia de recursos para su sostenimiento, además de que no venía del Estado encargado de su organización y funcionamiento. El único esfuerzo institucional que tuvo relativo éxito fue el realizado por Otero en la penitenciaría de Jalisco y que concluyó en los primeros años del régimen porfirista. Esta experiencia puede considerarse con justicia como el primer experimento en el lento proceso de formación del sistema penitenciario mexicano bajo el régimen de Auburn y que dejo su huella en distintos nive-

común implicaba la posibilidad de transformar la cárcel en fábrica, además de introducir la obligatoriedad de la educación, la disciplina y modalidades de tratamiento y rehabilitación de los delincuentes. Ibid. les de la administración carcelaria. A la par, se iniciaban los trabajos de la penitenciaria de Puebla.

Años después, en 1848, durante la administración de José Joaquín Herrera, que duraría hasta 1851, el Congreso de la Unión expidió una disposición titulada Ley Penitenciaria, la cual normaba, entre otras cosas, la forma de proveerse de recursos para la construcción de la moderna cárcel del Distrito Federal y Territorios. El sistema que se preescribía era el de Filadelfia. En 1850, bajo los lineamientos de dicha ley, el arquitecto de origen español Lorenzo de la Hidalga presento un proyecto de edificio carcelario. Sin embargo, no hubo ningún resultado concreto.

En 1853, José María Bellozi dio a conocer al gobierno del Distrito Federal su proyecto carcelario, pero fue rechazado por las autoridades respectivas, pues años antes la había sujetado al examen del gobernador de Michoacán, quien lo rechazó por sugerencia de Mariano Otero. Eduardo Griffon hizo lo propio en 1855. Ambos planes se diseñaron conforme al modelo de Auburn.

En noviembre de 1867, el Congreso determinó los mecanismos para obtener fondos suficientes -dolor de cabeza de las autoridades responsables de la construcción de una penitenciaría en el Distrito Federal- e iniciar las obras de la penitenciaría; dirigió una excitativa a los gobernadores para que informaran sobre la situación de sus estados con relación a dicho tema. Un año después, a petición de la representación nacional, la Escuela 
de Bellas Artes presentó su propuesta en la cual combinaba los métodos de Filadelfia y Auburn. ${ }^{48}$

En 1871, siendo secretario de Gobernación, José María Castillo Velasco envió a la Cámara de Diputados una iniciativa en la que consideraba que la penitenciaría era "la más noble y santa de las aspiraciones de los hombres". Ese mismo año se expidió el código penal mexicano, en el que se prescribía un sistema mixto

basado en los resultados poco satisfactorios obtenidos por la aplicación práctica (sic) de los principios constitutivos de Auburn, Filadelfia y Croffton, consistentes en un mismo medio, la comunicación o el aislamiento para la enmienda de toda clase de delincuentes. ${ }^{49}$

El código dispuso la creación de cinco departamentos: educación correccional, corrección penal, arresto, prisión y libertad preparatoria.

Aismismo, el gobierno mexicano mostró interés en instaurar el sistema penitenciario y en conocer otro tipo de experiencias a nivel internacional y envió delegaciones a los distintos congresos internacionales penitenciarios o bien comisionó a personajes prominentes dedicados a promover un sistema carcelario único. En 1872 se efectuó el primero de ellos en Londres y fue especialmente importante la presencia de nuestro país, representado por el doctor Enoch $\mathrm{C}$. Wines, director de cárceles de Estados Unidos, teólogo conservador y fundador del llamado

48 Macedo, "Municipio", 1902.

49 Medina y Ormaechea, México, 1892.
Movimiento Reformador, que se proponía instalar la disciplina fabril entre las masas "flojas y viciosas de las ciudades industriales de la posguerra civil". Su movimiento tuvo auge entre 1865 y 1900 , en coincidencia con el ascenso del porfiriato. ${ }^{50}$ También estuvo pre. sente en reuniones internacionales sobre caridad y filantropía, en las cuales se exponían, con gran optimismo, los avances de México en la atención social a los pobres. ${ }^{51}$

Al mismo tiempo que se buscaban afanosamente las causas de la mendicidad, la elite política elaboraba el pensamiento crimonológico en su esfuerzo por descubrir los motivos individuales y sociales que llevaban al mundo de la delincuencia. Para unos las razones había que buscarlas en la naturaleza y en el medio social en que habían crecido los criminales. Ambos factores habían creado seres amorales y cínicos, antisociales, formando un estado morboso colectivo, un mundo del subsuelo humano primitivo y caótico con una baja zona moral e intelectual. 52

Para otros, no había que buscar las causas de la criminalidad sino com-

50 Olmo, América, 1981, pp. 54-81. México estuvo presente en los tres congresos internacionales: en Londres en 1872, en Estocolmo en 1878 y en Roma en 1885 .

5l Archivo General de la Nación (AGN), Gobernación, sección 2a., exps. 880, 19, 1 y 885 1,3 ; sección 1a., $900,1,2$ y $9036,1$.

52 Urbina, Cronicas, 1946, pp. 3-14. Según Urbina, los delincuentes eran "ogros devoradores de carne, recién salidos de la selva primitiva, insaciables y furiosos, que ven en cada agrupación humana un conjunto de vidas que destruir y que les pertenecen como botín de guerra para contener su liviandad y sus apetitos". 
prender los motivos del criminal. A éste se le juzgaba como un enfermo del alma y del cuerpo y, por añadidura, habría que anteponer el castigo a la necesidad de higienizar su mente y su cuerpo, aliviarlo moralmente $y$ atenderlo físicamente mediante el trabajo. 53

Otros más expresaban cierto escepticismo sobre estas posiciones. Se preguntaban si en realidad padecían una enfermedad, y si ello era cierto iera posible su tratamiento y cura? En todo caso, se debía evitar que los enfermos contagiaran a otros que adquirieran el mal. La tarea, por tanto, tenía que ser doble: contener la criminalidad y evitar su proliferación. ${ }^{54}$

En opinión de las autoridades del Distrito Federal "el delito es una perturbación del orden moral de la sociedad" y por ello eran indispensables los lugares de segregación, en particular las cárceles, pero aquéllas no podían reducirse a ser sitios de castigo sino "casas de salud en las que los mismos delincuentes como enfermos morales se curaran y corrigieran". .5

Ambas posiciones sostuvieron que una de las causas fundamentales, atribuidas al medio social, era el alcoholismo porque provocaba la degeneración física y moral del hombre. El

53 Peña, "Cárceles", 1957, pp. 143-148.

54 Roumagnac, Criminales, 1904, pp. 25-27. Este autor sostenía: "En buena hora que demos un lugar al crimen, pero recordando que $\epsilon$ sta no es la enfermedad en sí misma, sino su resultado, su síntoma externo y que no porque ataquemos aquél, hacemos desaparecer ésta, que queda latente y dispuesta a desarrollarse cuando la ocasión o el medio le sean propios."

55 Ramón Fernández, Diario Oficial, núm. 196,18 agosto 1881 . robo, los crimenes pasionales y "los matadores de mujeres" eran los estragos más frecuentes de esa degene. ración. ${ }^{56}$ Para evitar que sus efectos continuaran como fuente de vicios, de desorganización y abandono familiar, de vagancia y, en general, de aumento de delitos se expidió el 16 de junio de 1876 un decreto contra la embriaguez en el que se autorizaba a las autoridades policiacas la represión "sin la mayor dilación" y una viligancia estrecha en los expendios de pulque y licores, prohibiéndose a los policías su permanencia en ellos sin justa razón y a riesgo de su "violenta destitución". 57

Por ello preocupaban tanto las condiciones de vida en las prisiones y en las instituciones de beneficencia pública y privada, ya que representaban sitios donde se reproducían todas las condiciones para que la enfermedad se extendiera y contagiara a quienes las habitaban.

En 1875, el médico e higienista Francisco Javier Peña expuso la situación de ruina de las cárceles mexicanas. El régimen carcelario se había reducido a una escuela de criminales, a un lugar de enseñanza para nuevos delitos, así como un sitio para el aprendizaje de "nuevas excitaciones y vicios". Las cárceles debían convertirse en centros de rehabilitación y regeneración y no de vindicta pública. La tesis sobre la pena de muerte, la ley del talión, etcétera, eran métodos de otros tiempos; el siglo XIX era el siglo de la ciencia, del humanitarismo y de la defensa de los derechos del hombre.

56 Boletin de Policta, 13 febrero 1910; Sesto, México, 1909

57 Islas Bustamente, Colección, 1884, vol. 1. 
Peña representa un pensamiento criminológico más elaborado y, por ende, una propuesta penitenciaria más acabada. Regresó a la formulación de que la sociedad tiene un compromiso con los reos y que la ley que debiera evitar los delitos, "se conforma con hacer anatemas sobre los reos; la sociedad que debiera curar a sus miembros se contenta con mandarlos al tiradero". Introdujo un nuevo elemento dentro de las particularidades del sistema penitenciario. Éste tenía que considerar la importancia de la higiene mental, y la cura psicológica del preso, enfermo moral que sólo podía aliviarse si contaba con las condiciones carcelarias adecuadas. Los elementos esenciales de la cura moral del recluso eran la alimentación balanceada y el trabajo colectivo en talleres. En suma, el régimen carcelario "debe ser una escuela donde las artes y los oficios marchen al lado de la ilustración del pensamiento". 58

El 29 de septiembre de 1900 , la inauguración de la penitenciaría del Distrito Federal culminó los esfuerzos de autoridades y altruistas por hacer un régimen carcelario más apegado a las corrientes reformistas del siglo XIX. Se ponía fin a una de las aspiraciones más permanentes de los reformadores de las cárceles y presos y de la elite gobernante. Según explicó Miguel Macedo, al dirigir el discurso inaugural, el sistema penitenciario declaraba entre sus objetivos:

Aquí se elaborará la corrección del delincuente $[. .$.$] orientado a la corrección$ moral y que abarque todas las fases de

58 Peña, “Cárceles", 1957, p. 173.
La vida del hombre a quien la justicia ha declacado delincuente, desde la celda que ha de ocupar y la alimentación que ha de recibir, hastā sus comunicaciones con el exterior. 59

Años después, otro de los proyectos más importantes de la reorganización institucional fue la inauguración del Hospital General que, según las autoridades sanitarias y los cronistas de la época, en nada envidiaba a los mejores del mundo. Posteriormente, se haría lo propio con el Manicomio General, que también provocó los desvelos de las autoridades y filántropos, representando una de las instituciones más importantes y necesarias para culminar dicho proceso reformista. ${ }^{60}$

Durante el porfiriato se fundaron las instituciones sociales más adecuadas a las necesidades de la elite política mexicana para ejercer el control social sobre las clases trabajadoras y las clases peligrosas.

\section{BiBLIOGRAFIA}

-Bastian, Jean-Pierre, "Metodismo y clase obrera en el porfiriato", Historia Mexicana, vol. xxuI, núm. 1 (129), julio-septiembre 1983.

, Los disidentes. Sociedades protestantes y revolución en México, 1872 . 1911, Fondo de Cultura Económica/El Colegio de México, México, 1989.

-Fernández Castelló, Justino, Las fundactones de beneficencia privada bajo su aspecto económico y jurídico, Tip., Lit., y Encuadernación de Ireneo Paz, México, 1897.

\$9 Macedo, "Discurso", 1900.

60 González Navarro, Historia, 1957, p. 131. 
-Foucault, Michel, Vigilar y castigar, Siglo XXI Editores, México, 1981.

García Icazbalceta, Joaquín, Informe sobre establecimientos de beneficencia $y$ corrección de esta capital, su estado actual, noticia de sus fondos, que desde luego necesitan y plan general de su arreglo presentado por José María Andrade. Escrito póstumo de..., Moderna Librería Religiosa, México, 1907.

González Navarro, Moisés, Historia moderna de México, vol. vI, Porfiriato. Vida social, Hermes, México, 1957.

, Anatomía del poder en México, El Colegio de México, México, 1977.

La pobreza en México, El Colegio de México, México, 1985.

-Gortari Rabiela, Hira de y Regina Hernández Franyuti, La ciudad de México y el Distrito Federal. (1824-1928), Departamento del Distrito Federal/Instituto Mora, México, 1989.

Guerrero, Julio, La genésis del crimen en México, Librería de la Vda. de Ch. Bouret, París, 1901.

-Guglielmi, Nilda, Marginalidad en la Edad Media, Editorial Universitaria, Buenos Aires, 1986.

-Himmerlarf, Gertrude, La idea de la pobreza. Inglaterra a principios de la era industrial, Fondo de Cultura Económica, México, 1988.

-Islas Bustamante, Nicolás, Colección de leyes $y$ disposiciones gubernativas, municipales y de policía, vigentes en el Distrito Federal formado por acuerdo del C. Gobernador Carlos Rivas, Imprenta y Litografía de Ireneo Paz, México, 1884.

-López Portillo y Rojas, José, Escritos económicos, Tipografia de El Tiempo, México, 1910.

Macedo, Miguel, "Discurso pronunciado por el Lic..., director presidente de la penitenciaría", en Penitenciaría en México, Imprenta de Francisco Díaz de León, México, 1900.

"El municipio. Los estableci- mientos penales. La asistencia pública", en Justo Sierra, México, su evolución social, J. Ballescá, México, 1902, tomo 1, vol. 2.

-Martínez de Castro, Antonio, "Exposición de motivos del Código Penal en el Distrito Federal y Territorio de B. California", Criminalia, año XXXıv, núm. 3, México, 30 de marzo de 1868.

-Medina y Ormaechea, Antonio, México ante los Congresos Internacionales Penitenclarios, Secretaría de Fomento, México, 1892.

-Mellosi, Darío y Massimo Pavarini, Cárcel y fábrica. Los origenes del sistema penitenciario (siglos XVI-XIX), Siglo XXI Editores, México, 1980.

-Mendoza Ramírez, Guadalupe, "Presos, delitos y castigos", tesis de maestría en historia, Universidad Autónoma Metropolitana/Lztapalapa, México, 1989.

-Mollet, Michel, Pobres, bumildes y miserables en la Edad Media, Fondo de Cultura Económica, México, 1988.

-Novo, Salvador, Un año bace ciento. La ciudad de México en 1873, Editorial. Porrúa, México, 1973.

-Olmo, Rosa del, América Latina y su criminología, Siglo XXI Editores, México, 1981.

-Otero, Mariano, Obras del Lic.., Imprenta de Ignacio Otero, México, 1959.

-Peña, Francisco Javier, "Las cárceles en México en 1875", Criminalia, año XXv, núm. 8, 1957.

-Peza, Juan de Dios, La beneficencia en México, Imprenta de Francisco Díaz de León, México, 1881.

-Romero, Félix, El sistema penttenciario tratado por el Lic..., Imprenta Moderna, México, 1897.

-Roumagnac, Carlos, Los criminales en México, Tipografia El Fénix, México, 1904.

-Santoni, Pedro, "La policía de la ciudad de México durante el porfiriato: los primeros años (1876-1884)", Historia Mexicana, vol. XxxIII, núm. 1 (129), julio-septiembre 1983. 
-Secretaría de Gobernación, Beneficencia privada. Leyes y reglamentos, México, Imprenta del Gobierno en el ex Arzobispado, 1899.

-Sesto, Julio, El México de Porfirio Díaz, Valencia F. Sempère y Compañía Editores, Madrid, 1909.

-Sierra, Justo, Obras, Universidad Na- cional Autónoma de México, México, 1948 , vol. IV.

-Urbina, Luis G., Crónicas, Editorial Universitaria, México, 1946.

-Zavala, Lorenzo de, Ensayo bistortco de las revoluciones en México desde 1808 basta 1830, Fondo de Cultura Económica, México, 1985 (edición facsimilar). 


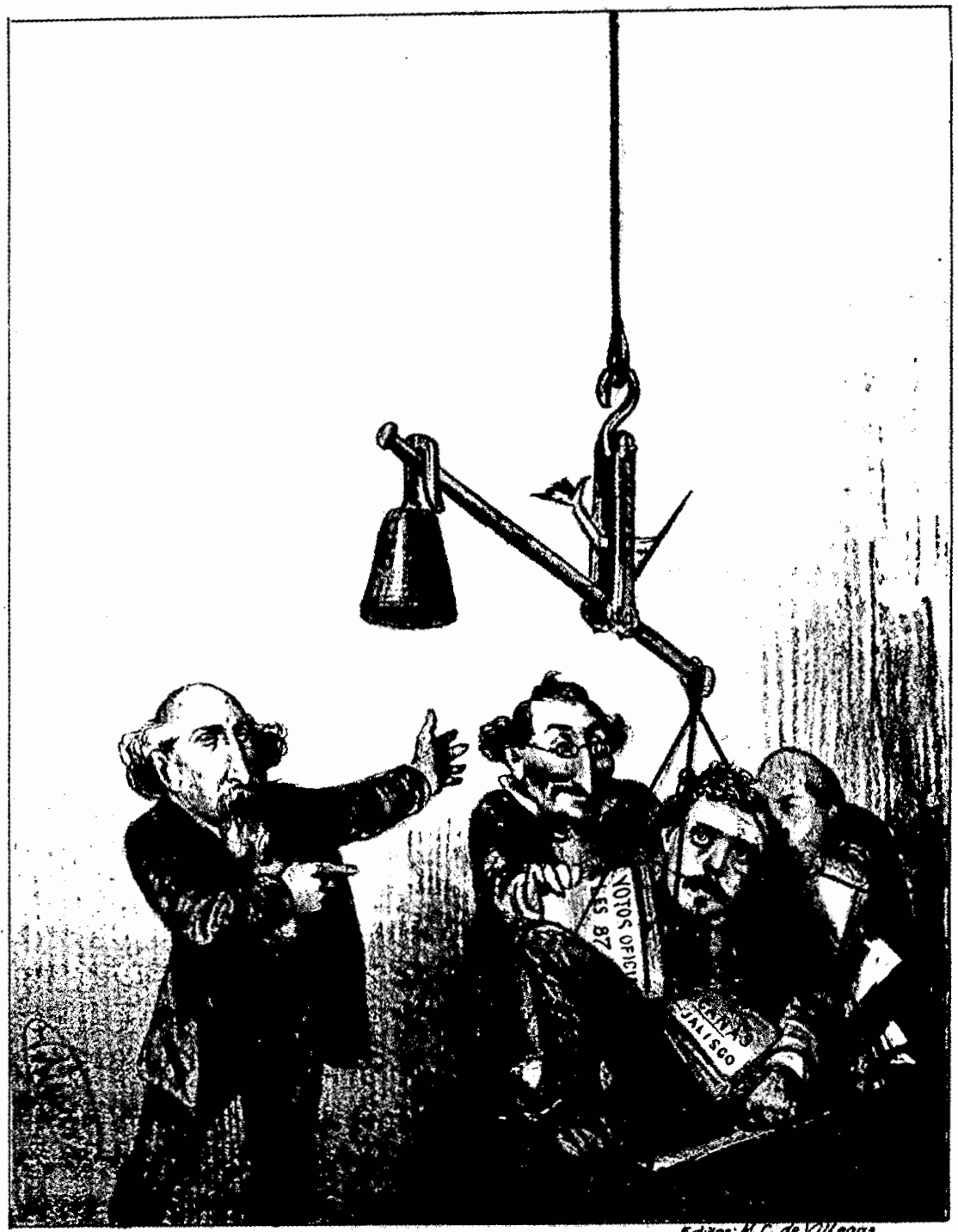

Fditarthathregat.

Asími galgo las pesca....... por que Jalisco nunca piarde, y cuando pierde arrebata. 